\title{
'I Just Keep Quiet': Addressing the Challenges of Married Rohingya Girls and Creating Opportunities for Change
}

\author{
Silvia Guglielmi ${ }^{1}$ (D) $\cdot$ Khadija Mitu $^{2} \cdot$ Jennifer Seager ${ }^{3}$
}

Accepted: 21 July 2021 / Published online: 25 August 2021

(C) The Author(s) 2021

\begin{abstract}
Child marriage among Rohingya refugees living in Cox's Bazar, Bangladesh, is driven by economic strain and deep-seated gender norms. Mounting evidence shows the harmful effects of child marriage, and SDG 5.3 underpins a global impetus to eliminate it. Our mixed-methods research across refugee camps in Ukhia and Teknaf Upazilas included quantitative surveys and qualitative interviews (IDIs) with married and unmarried girls and their parents, and focus group discussions (FGDs) with parents of married and unmarried girls, boys, and community members to understand Rohingya perspectives on child marriage, the role of norms in displacement, and how married girls' capabilities are impacted by their marital status. We find that married girls face increased gender-based violence (GBV) risks, including intimate partner violence (IPV), and greater mental distress. While norms are shifting for older Rohingya women, married girls are excluded from social participation or personal growth beyond the household. We argue that involving married girls in community activities and vocational training designed according to local market needs may empower married girls.
\end{abstract}

Keywords Rohingya refugees $\cdot$ Child marriage $\cdot$ Adolescence $\cdot$ Gender norms · Empowerment

Silvia Guglielmi

s.guglielmi.gage@odi.org

Khadija Mitu

mituju@gmail.com

Jennifer Seager

jseagermuz@gwu.edu

1 Gender and Adolescence: Global Evidence Programme, Overseas Development Institute, London, UK

2 Department of Anthropology, University of Chittagong, Chittagong, Bangladesh

3 Milken Institute of Public Health, George Washington University, Washington, DC, USA 


\section{Résumé}

La pratique du mariage d'enfants au sein de la communauté des réfugié-es Rohingyas vivant à Cox's Bazar, au Bangladesh, est motivée par des tensions économiques et des normes de genre profondément enracinées. Les effets néfastes du mariage d'enfants sont de plus en plus évidents, et l'ODD 5.3 sous-tend un élan mondial pour éliminer cette pratique. Nos études à méthodes mixtes dans les camps de réfugié.es d'Ukhia et de Teknaf Upazilas comprenaient des enquêtes quantitatives et des entretiens qualitatifs (entretiens approfondis) avec des filles mariées et non mariées et leurs parents, et des discussions de groupe (FGD) avec des parents de filles mariées et non mariées, avec des garçons et des membres de la communauté afin de comprendre les points de vue des Rohingyas sur le mariage d'enfants, le rôle des normes pour les personnes déplacées et la mesure dans laquelle les capacités des filles mariées sont affectées par leur état matrimonial. Nous constatons que les filles mariées sont confrontées à des risques accrus de violence sexiste (violence basée sur le genre ou VBG), y compris la violence conjugale (violence exercée par un partenaire intime ou VPI) et une plus grande détresse mentale. Alors que les normes évoluent pour les femmes Rohingya plus âgées, les filles mariées sont exclues de la participation sociale ou de la croissance personnelle au-delà de la sphère domestique. Nous soutenons que l'implication des filles mariées dans les activités communautaires et les formations professionnelles conçues en fonction des besoins du marché local peut permettre l'autonomisation et l'émancipation des filles mariées.

\section{Introduction}

Child marriage, defined as marriage before the age of 18 , is a recognised form of gender-based violence (GBV) and can perpetuate other forms of GBV (Girls Not Brides and ICRW 2016). The Inter-Agency Standing Committee guidelines on GBV highlight that when gender-based discrimination intersects with other dimensions of vulnerability, including age, the exposure to multiple forms of GBV can escalate (IASC 2015; Mourtada et al. 2017). Child marriage can lead adolescent girls to face increased risks of intimate partner violence, for instance (IASC 2015).

Though rooted in cultural tradition and gender inequality, child marriage is exacerbated in humanitarian contexts, including displacement. Increased household poverty in displacement is associated with daughters being married off at an earlier age as parents struggle to provide for them (Ainul et al. 2018; Melnikas et al. 2020; Plan International and GPS 2018; ISCG 2017). Additionally, real or perceived insecurity for adolescent girls in refugee settings results in earlier marriage to safeguard their honour and purity, which may be jeopardised if left unmarried (Presler-Marshall 2020; CARE International UK 2015; Freccero and Whiting 2018; Save the Children 2019; Women's Refugee Commission (WRC) 2016; UNFPA 2017; UNHCR et al. 2018; Mazurana and Marshak 2019; Girls Not Brides 2018). A recent study conducted by UNFPA and UNICEF reported that gender discrimination, inadequate implementation of laws and camp policies, and economic insecurity are the key drivers that influence Rohingya life in the camp setting and contribute to an enabling environment for child marriage (Leigh et al. 2020). 
Globally, efforts to end child marriage have been expanded over the past decade. The 2017 Human Rights Council Resolution on Child Marriage in Humanitarian Settings (OHCHR 2017) recognises child marriage as a violation of human rights, as well as a form of violence against children and women, and calls for strengthened efforts to prevent and eliminate this harmful practice. Likewise, efforts to meet Sustainable Development Goal (SDG) target 5.3, which calls for the 'elimination of all harmful practices, such as child, early and forced marriage and female genital mutilations', have led to an expanded knowledge base on drivers of child marriage in low- and middle-income countries (LMICs) and effective interventions to combat it. Notwithstanding notable exceptions (Leigh et al. 2020; Presler-Marshall 2020; Ainul et al. 2018; Melnikas et al. 2020; Plan International and GPS 2018) much literature does not address child marriage in humanitarian contexts (Mourtada et al. 2017; Murphy et al. 2016). Additionally, research and programming generally strive to combat the underlying drivers of child marriage and to prevent the practice, with fewer studies devoted to understanding the lives of already married girls.

This paper draws on mixed-methods data collected in 2019 as part of the Gender and Adolescence: Global Evidence (GAGE) programme in Rohingya camps in Cox's Bazar, Bangladesh. This paper primarily captures and compares the voices of married and unmarried Rohingya adolescent girls on their everyday life and distinguishes the challenges they face. The aim of the research is to understand adolescent, parental, and community perspectives on child marriage, the role of social norms vis-à-vis child marriage in displacement, and to evaluate diverse capability domains in the lives of displaced married girls. Our findings highlight that, while all adolescent Rohingya girls are marginalised from fulfilling their educational and employment trajectories, married girls face additional GBV risks, particularly in the form of IPV. We also find strong evidence suggesting worse mental health outcomes for married girls and greater distress in their lives. These findings fill an important gap in the literature, improving our understanding of norms and practices of child marriage among the Rohingya, that will help policy-makers and organisations design more tailored interventions to meet married girls' needs. The rest of the paper is organised as follows: "Background" section provides additional background on the Rohingya context and social norms, "Methodology" section discusses the conceptual framework and methodology, "Research findings" section presents the research findings, "Discussion" section provides discussion and "Conclusion" section concludes.

\section{Background}

Forced displacement worldwide has increased significantly over the past decade. The United Nations High Commissioner for Refugees (UNHCR) reported that by the end of 2019, over 79 million people were forcibly displaced as a result of persecution, conflict or generalised violence (UNHCR 2020). The Rohingya populationa stateless Muslim ethnic minority from Buddhist majority Myanmar-have been forced to flee their country over the past few decades due to grave human rights violations committed against them (UNHCR 2019a), and are widely known as one of 
the most persecuted, discriminated against, and overlooked minorities in the world (Ahsan et al. 2018; Kingston; 2015; Lewa 2008).

Although the Rohingya have resided in Myanmar's Rakhine state for generations, in accordance with Myanmar's restrictive 1982 citizenship legislation, they became de jure stateless in their own country (Ahmed 2010). In different waves throughout the 1970s, 1990s and 2010s, the Rohingya arrived in Bangladesh and sought refuge in Cox's Bazar, a coastal district located in the southeastern Chittagong division along Bangladesh's border with Myanmar (UNHCR 2019a). The most recent influx, which began in August 2017, dwarfed previous outflows, and in a few months, more than 740,000 Rohingya had crossed the border into Bangladesh. They settled into 32 camps located in Ukhia and Teknaf, two flood-prone sub-districts of Cox's Bazar (Ibid).

The stateless nature of the Rohingya population and political tensions between Bangladesh and Myanmar make it difficult for policy-makers to design and implement long-term interventions (Rahman and Mohajan 2019; Milton et al. 2017).

Among Rohingya refugees in Cox's Bazar, child marriage is commonly practiced and appears to have increased since their displacement (ISCG 2017; Ainul et al. 2018; Plan International and GPS 2018; ACAPS 2019a, b; UNHCR 2019b; Melinkas et al. 2020). A study on Rohingya socio-normative values and practices (Ripoll 2017) reports that the median age for a Rohingya woman to marry in Myanmar in 2016 was 20.7 years. While exact rates in displacement are hard to pinpoint, a nutrition sector Infant and Young Child Feeding in emergencies assessment found $41 \%$ of Rohingya mothers interviewed were married before the age of 18 (ACAPS 2019a) and UNHCR reports that over 50\% of Rohingya girls who fled Myanmar to numerous destinations in South East Asia since 2012, have married before 18 (UNHCR 2017).

Further contributing to its expansion, social practices such as child marriage appear to have been more tightly monitored in Myanmar, whereas the lack of systemic and compulsory registration of marriages for the Rohingya in Bangladesh has meant that "child marriages are more likely to occur and remain unnoticed" (UNHCR 2019b, p. 2). National marriage laws of Bangladesh were not immediately announced or enforced in the refugee camps after the 2017 influx, and marriages following religious ceremonies (without registrations) took place in the camps. These were well outside of the Bangladeshi legal system, and "contributed to a surge in child marriage for the first year and a half following displacement" (Leigh et al. 2020 , p. 8). Although government officials working in the Rohingya camps were given the responsibility to register and maintain marriage and divorce records from 2018, the registrations were not implemented in practice (UNHCR 2019b).

While the consequences of child marriage are equally not well documented among the Rohingya, in other refugee populations, it has been found to be a driver of other forms of GBV, limited future employment and increased social and emotional isolation for girls (Arab and Sagbakken 2019; Chakraborty 2019). Although not disaggregating by age, humanitarian sector reporting on Rohingya women point to an intensification of intimate partner abuse due to displacement-related concerns, including reduced livelihoods (GBV Area of Responsibility 2017; GBV Information Management System 2019). 
Limited reporting on IPV compounds the vulnerabilities facing married girls. An evidence review on Rohingya social customs found that 'domestic violence is perceived as a "family affair" to be solved by the family alone,' (Ripoll 2017, p. 4) leading to a silencing and normalizing of IPV. In the camps, community representatives known as majhis have, at times, hindered referral and redress mechanisms for victims of abuse (Akhter and Kusakabe 2014). Initially established as part of the 1990s Rohingya wave into Bangladesh, the majhis act as focal points in the camp blocks and support the Bangladesh government in administering the influx of people (ACAPS 2019b). Though abolished due to widespread corruption, the majhi system was reinstated following the 2017 influx. Majhis act as intermediaries for the individual offices of Camp in Charge (CiC), ${ }^{1}$ and have an extensive role including security, the handling of disputes, and channelling information to refugee populations (ACAPS 2019b; Sullivan 2020). The Protection Sector Working Group has reported that the majhi system hinders gender equality in the camps, and is marred by 'corruption, extortion and charging fees for access to humanitarian aid, including with instances of violence and GBV' (ISCG 2018, p. 2; Toma et al. 2018).

Potentially further exacerbating Rohingya girls' vulnerability to child marriage is the stringent religious tradition of purdah, documented in various townships in Rakhine state, Myanmar. Purdah (translated as 'veil') is a set of social expectations or norms to guide Muslim and Christian women's behaviour (Yusuf, 2014). It may refer to the physical segregation of living space, the covering of body and face, as well as the beliefs and values about expected or normative behaviour of women, restrictions on their movements, or requirements for their respectful and deferential behaviour in the presence of males within the home and outside in public areas (Hossain et al. 2017; Desai and Temsah 2014; Ripoll 2017). Research conducted on the prevalence of child marriage in Bangladesh found that, "child marriage prevalence is the highest among ever-married women who are conservative in terms of the practice of purdah" and that "practicing purdah... works as a deterrent for women's empowerment... [by restricting] women's mobility and interaction in society" (Hossain et al. 2017, p. 144). The study also found that daughters of parents who are conservative in practicing purdah have a higher prevalence of child marriage compared to those of parents who are liberal and that men prefer to marry religious women who practice purdah as they are considered as respectful (ibid).

Rohingya females who preserve purdah are believed to uphold the dignity of their family and household (Holloway and Fan 2018). There is some evidence, however, that this tradition may be eroding. Recent studies have found that although Rohingya men are reluctant about women and girls venturing outside the home to work, they would welcome them earning an income (Wake et al. 2019). It is also the case that in some contexts, displaced communities have, over time, assimilated gender norms

\footnotetext{
${ }^{1}$ In terms of authority and management, the Rohingya response is led and coordinated by the Government of Bangladesh who appoints the Relief the Refugee Relief and Repatriation Commissioner (RRRC) under the Ministry of Disaster Management. It is the RRRC who is responsible for the oversight of the Rohingya refugee population and appoints civil servants on a rotation basis as Camp-in-Charge (CIC) offices present in each individual camp who manage day-to-day affairs and disputes within the community, alongside the military (ISCG 2020, ACAPS 2019b).
} 


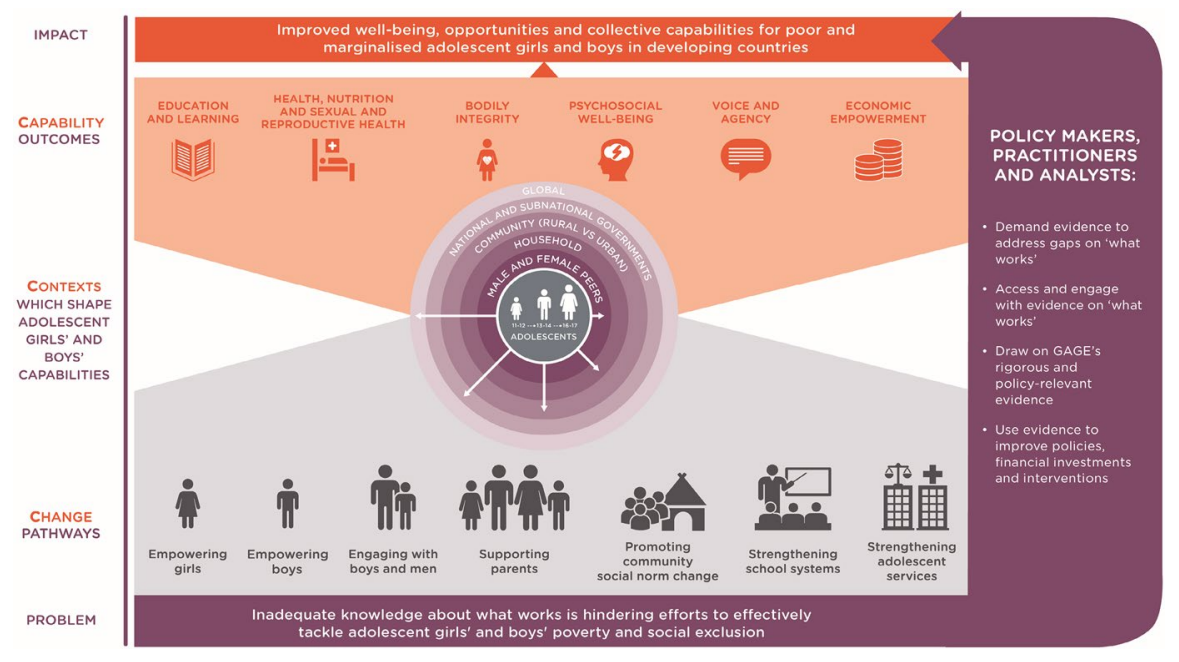

Fig. 1 GAGE '3 Cs' conceptual framework

of their host community (Kabeer et al. 2011 and Johnsdotter et al. 2009, as cited in Marcus and Harper 2014). ${ }^{2}$ While Bangladeshi married girls also face domestic abuse and discriminatory gender norms, purdah is less rigid among Bangladeshi communities and gender power dynamics appear to be shifting in many parts of the country (Hossain and Kabir 2001; Hossain 2012; Khosla 2009).

Finally, while recent work has highlighted the adverse effects of child marriage on girls' mental health, including increased social isolation, decreased self-esteem, and a lack of voice and agency (see Jones et al 2019a, b), research on the relationship between child marriage and psychosocial wellbeing remains underexplored, particularly in displacement. Although there are reports that in Rohingya culture psychological abuse within marriage is not necessarily perceived as violence (Ripoll 2017), the evidence base is limited. This is in contrast to the richer literature correlating child marriage with restricted educational opportunities and limited sexual and reproductive health knowledge (Siddiqi and Greene 2019).

\section{Methodology}

\section{Conceptual framing}

Our study follows GAGE's socioecological conceptual framework (see Fig. 1) which focuses on adolescents' multidimensional capabilities and constraints at

\footnotetext{
2 Though the Rohingya formally remain segregated from the rest of Bangladesh, interaction between Rohingya and Bangladeshis is commonplace.
} 
different stages of the life course through the interconnectedness of capabilities, contexts, and change strategies (Baird et al. 2020; GAGE consortium 2019).

As discriminatory norms become more entrenched in adolescence, the capabilities lens helps to distil the extent to which adolescents develop, and in which domains. Findings are framed alongside the bodily integrity freedom from violence and psychosocial wellbeing capability domains. The former domain emphasises the protection of adolescents from physical and sex- and gender-based violence, including child marriage, and recognises that risks to bodily integrity are amplified during the second decade of life, especially in humanitarian contexts. Intersecting with freedom from violence, the psychosocial wellbeing domain recognises that adolescent girls in particular may face increased social isolation as they age, with restricted friendships, limited mobility, and sparse opportunities for support outside the confines of their homes, all impacting their psychosocial wellbeing (GAGE Consortium 2019). Context and change strategies are helpful in understanding that adolescent outcomes are dependent on contextual realities at household, community, national and global levels. By situating Rohingya married girls in their socioecological context, this research distils how marriage impacts girls' capabilities in displacement, and how social norms and contextual realities impacts the experience of child marriage.

To analyse social norms affecting Rohingya adolescent girls' lives, we looked to feminist scholars who distinguish gender norms from broader social norms. Feminist scholars conceptualise the relationships between norms, patriarchy and power, and view gender norms as intrinsic to the reproduction of gender-inequitable ideologies, relationships and social institutions (e.g. Keleher and Franklin 2008; Munoz Boudet et al. 2012; Rao 2012; Sen et al. 2007; Watson 2012). Beginning in childhood and continuing through adolescence into adulthood, unequal gender norms are taken for granted and are unquestioned (Bourdieu 1977). The normalisation of gender inequalities and practices takes place in the realm of 'doxa' according to Bourdieu, whereby 'the natural and social world appear as self-evident', implicating that 'every established order tends to produce (to very different degrees and with very different means) the naturalization of its own arbitrariness' (1977, p. 164). It is useful to view Rohingya experiences such as purdah and child marriage as the product of internationalised gender norms and this can provide a more complete lens through which to analyse them.

Finally, we acknowledge critical debates around girls' empowerment and gender equality, as well as their intersection in humanitarian settings. While girls' empowerment has often been constructed as an instrumental outcome of development programmes geared towards increasing the human capital of girls, these conceptions lack the nuance required to view empowerment through its true complexities: as a dynamic process, often lacking linearity, and as an intrinsic outcome which tackles structural power dynamics and promotes choice (Cornwall 2018; Pincock 2018; Murphy 2013; Kabeer 2005). Acknowledging the multidimensional nature of empowerment is particularly critical in such a pressured and unstable environment such as displacement. 
Table 1 Mixed-methods research sample

Quantitative fieldwork

No. of respondents

\begin{tabular}{ll}
\hline Survey married Rohingya girls (11-18 years) & 92 \\
Survey unmarried Rohingya girls (15-18 years) & 169 \\
Total & 260 \\
\hline & Qualitative fieldwork \\
& No. of respondents \\
\hline IDIs married Rohingya girls (15-19 years) & 10 \\
IDIs unmarried Rohingya girls (15-19 years) & 17 \\
IDIs parents of married and unmarried Rohingya adolescents & 12 \\
FGDs Rohingya adolescent girls and boys (10-19 years) & 12 \\
FGDs Rohingya parents of adolescents and wider community members & 6 \\
Total & 57 \\
\hline
\end{tabular}

\section{Research sample}

Survey data for this study are nested within the Cox's Bazar Panel Survey (CBPS 2019), a partnership between GAGE, the Yale MacMillan Center Program on Refugees, and the World Bank's Poverty and Equity Global Practice, to understand the existing landscape of displaced Rohingya and host communities in Cox's Bazar. GAGE collected data from a representative sample of 2,086 households with an adolescent aged 10-12 or 15-17 between April and July 2019 across both camps (940 households) and host communities (1146 households), and an additional purposeful sample of 194 households (131 in camps and 63 in host communities) with married adolescents and adolescents with disabilities. ${ }^{3}$

While this article draws on quantitative data from the overall GAGE sample of Rohingya adolescents living in camps to provide context, we focus primarily on a subsample of 92 married Rohingya adolescent females aged 11-18 and 169 unmarried adolescent females aged $15-18$ in camps. ${ }^{4}$ Within these samples, we further collected data using interactive qualitative interviews (IDIs) from 10 married Rohingya girls and 17 unmarried older Rohingya girls (aged 15-19) (Baird et al. 2020). The findings reported also stem from IDIs gathered from 12 parents of married and unmarried Rohingya adolescents. This was supplemented with 12 focus group discussions (FGDs) with girls $(n=61)$ and boys $(n=40)$ engaged separately, and six FGDs with female $(n=51)$ and male $(n=48)$ parents and community members, to

\footnotetext{
${ }^{3}$ The overall CBPS sample comprises a representative sample of 5,020 households. See Gugliemi et al. (2020) for more detail on the sample.

${ }^{4}$ Because only 8 of the 92 married adolescents were under the age of 15 (4 of which were 14), we restricted the unmarried sample to be 15 years or older in order to make the comparison group of unmarried adolescents more similar to the married adolescents.
} 
better understand the perceptions and norms surrounding marriage (see Table 1 for a detailed breakdown of our married and unmarried sample).

Verbal consent was obtained from all respondents. Informed consent was obtained from the parents/guardians of those who are legal minors, but also assent from adolescents themselves. Surveys and interview questions were initially translated from English into Bangla and then translated into the Chittagonian local dialect (which is very similar to the Rohingya language) and subsequently piloted. Quantitative and qualitative data were collected during face-to-face interviews by enumerators and interviewers who were the same sex as the respondent. Enumerators were trained on working with adolescents, including child protection policies, best practices in conducting fieldwork, and on the GAGE research design and conceptual framework.

Research ethics approval was secured from the Overseas Development Institute's Research Ethics Committee, George Washington University IRB (protocol $\# 071,721$ ), and in Bangladesh through Innovations for Poverty Action IRB (protocol $\# 14,742$ ).

\section{Research sites}

Baseline fieldwork took place between April and October 2019 in all 32 unregistered refugee camps across the Cox's Bazar district (25 in Ukhia Upazila and 7 in Teknaf Upazila). Qualitative fieldwork took place across three camps selected based on a mapping exercise. Drawing on ISCG metadata, we were able to calculate the number of humanitarian partners implementing services per camp, camp population size, and the number of adolescent beneficiaries reached in each camp. Based on the ratio of beneficiaries being targeted, we selected a, 'underserved' site for adolescent (camp 2E), a 'middle-served site' (camp 24) and a 'best-served' site (camp 12).

\section{Data analysis}

We constructed a set of indicators to capture the experience of married and unmarried older adolescents in the camps within two of GAGE's six capability domains: bodily integrity and psychosocial wellbeing. Using these indicators, we explore differences in means between married and unmarried girls. All quantitative analysis was performed using STATA statistical software.

A team of GAGE analysts and field researchers at Chittagong University undertook qualitative data gathering, data management, and data analysis. IDI and FGD transcripts were translated from Chittagonian into Bangla then into English. Raw transcripts were read and coded using the qualitative analysis software package MAXQDA, following a codebook shaped around the GAGE conceptual framework and the research tools. Data analysis was done in collaboration between research teams at GAGE and Chittagong University. During qualitative data analysis, care was taken to identify cross-cutting themes while also allowing space for unique voices more specific to individual experiences. 


\section{Research findings}

Three years on from the mass influx into Bangladesh, and entirely dependent on humanitarian aid for survival, there are few opportunities for married and unmarried Rohingya adolescent refugee girls to develop their capabilities. Only 3\% of girls are engaged in any education and only $5 \%$ have engaged in paid work in the past 12 months, indicating access to opportunities for advancement is scarce. However, data indicate that married girls face additional constraints to developing their capabilities.

\section{Norms and attitudes towards child marriage}

Our qualitative data found that norms and attitudes related to child marriage in the camps are highly conservative, with safety concerns, economic strain, and cultural and religious norms among their main drivers. As the mother of an 18-year-old young woman from camp 12 explained, 'Why [wouldn't] I marry her off? It is the rule of Islam. Will anyone marry her when she gets older?' Marriage in the camps occurs early-among our married sample, the average age at marriage was 15 years with the youngest age being 11 years old. Echoing findings from other studies, nearly all of the married girls in our sample were married after arriving in Bangladesh (Ainul et al. 2018; Melnikas et al. 2020; Ripoll 2017; ISCG 2017; ACAPS 2019b; UNHCR 2019b), with only 13 of the 92 married adolescents having married prior to their arrival date. ${ }^{5}$

Boys tend to marry when they are older, as they face fewer perceived genderbased risks, so, unlike girls, do not require the 'protection' offered by marriage. This is illustrated by the average age of marriage of the spouses of our married girls, which is 21 years. Moreover, our qualitative data show that boys are meant to contribute to household finances as they progress through adolescence, thus the economic strain they place on the household fades as a driver. This was confirmed by our survey data, which found that up to $26 \%$ of Rohingya adolescent boys had worked for a wage in the past year-mostly as camp porters, shop assistants, or driving/fixing rickshaws. Moreover, while the random sample found that $12 \%$ of Rohingya girls aged 15-18 were already married, only $6 \%$ of Rohingya boys of the same age are.

Our qualitative findings on norms and attitudes towards child marriage reflect the widespread practice of purdah, banning girls from venturing outside their homes unaccompanied when they reach puberty. This came out strongly in qualitative interviews with adolescents and parents. As related to marriage, staying at home is meant is to protect girls' honour and secure good marriage prospects. A 17-year-old married girl in camp 2E explained, "No, I don't [go out] because people say a lot of things... Since I stay within veil that is why Allah keep me this beautiful way." The

\footnotetext{
5 Although we do not directly ask adolescents where they were married, we use their current age, age at marriage, and date of arrival to Bangladesh to determine whether the marriage occurred prior to arriving in Bangladesh.
} 
quantitative data support this, where only $11 \%$ of girls leave their camp block at least once per week and $56 \%$ of girls (68\% of married girls and $50 \%$ of unmarried girls) face restrictions on how they dress when leaving the home. This is in contrast to older Rohingya boys, $85 \%$ of whom leave the camp block at least once per week and only $8 \%$ of whom face restrictions on dress.

Our qualitative data found evidence that economic insecurity the Rohingya face could be sowing the seeds for norm change around purdah. The dire economic circumstances faced by Rohingya families since displacement has pushed some women (and some adolescent girls) to take on income-generating opportunities and participate in skills training, as explained by a 16-year-old married girl in camp 2E, "After coming here women started going outside to do jobs. In our Burma, women can't go to jobs if you even give fifty thousand taka as salary yet they won't go to jobs as they aren't allowed to show their face to anyone. Women couldn't even go out of the door of their house in Burma. But now those women are going outside to do jobs....After coming here they broke all the rules... If I get any job it will be make me happy." Approximately half of the married girls in our qualitative sample would welcome such opportunities and show responsiveness towards venturing outside the home. A 17-year-old married girl in camp 24 claimed, "I have to do something, I have to do a job. I can't bring food [home] if I listen to everyone. If people want, they can defame me. But, I can't sit at home... I have to fill my stomach. So, I can't stay at home."

Though married and unmarried girls' experiences in accessing income-generating opportunities and training are low overall, our data present a few exceptions. Unmarried girls are significantly more likely to report benefitting from programmes that provide employment for youth or economic skills building (9\% vs 5\%). Our data indeed highlight the limbo faced by married girls, whereby their marital status and childcare demands translate into missed vocational training opportunities provided to 'adolescents', including sewing, tailoring and life skills classes, while equally missing out on opportunities provided to 'women' of an older age band, such as volunteering for a variety of camp structures and participating in cash-for-work schemes (ISCG et al. 2019). As stated by and 18-year-old married girl in camp 2E, "Yes [I earned money by sewing]. Before my marriage.", while a 17-year-old married girl in camp 12 clarified, "The girls who live here, down the hill, are doing jobs. [But] they are 20 or 25 or 30 years old."

\section{Freedom from violence}

Overall reporting of GBV (defined in our survey as harassment, assault, rape, or domestic violence) in the last 12 months is low at $6.5 \%$ across both married and unmarried girls. However, this likely does not paint a complete picture of their experiences. Firstly, married girls are twice as likely to have experienced GBV (11\% of married girls compared to $4.5 \%$ of unmarried girls) and $3.7 \%$ of married girls report experiencing rape or sexual abuse (compared to $1.3 \%$ of unmarried girls). Further, when asked about other members of the community, $19.4 \%$ of married and unmarried adolescents report having witnessed rape or sexual abuse and $71 \%$ report hearing about such instances. This latter discrepancy is suggestive that Rohingya girls, 
in general, do not readily disclose their own experiences of GBV in quantitative surveys or do not consider certain forms of violence as GBV when answering about their own lives.

Most of our qualitative interviews find that married girls experience physical abuse by their husbands and in-laws if they show disrespect towards what is culturally viewed as wives' duties. A 16-year-old girl from camp $2 \mathrm{E}$ recounted being abused by her husband and his family upon refusing to eat all the food brought by her sister-in-law during Eid celebrations: 'My husband beat me up with a stick for not eating the foods she brought. Then I wasn't given food and water for three or four days.' The apparent acceptability of IPV towards married girls appears endemic, as a 16-year-old unmarried girl in camp $2 \mathrm{E}$ crystallised a common sentiment: 'Some husbands torture their wives. This is very common here. I have heard a lot about this from many persons. When the wives don't listen to their husbands, they are beaten.' Physical violence in the form of beatings is the most common type of IPV experienced by married Rohingya girls in our qualitative sample.

Married girls simply do not know whether or how to report IPV. Partially, this stems from cultural notions silencing girls' voices, as an 18-year-old married girl from camp 12 explained: 'What will we say? Can we badmouth men or beat them up? They beat us. Why will I say anything? When I say anything to my husband, he beats me. So I keep quiet... When I ask him why he beats me, he says that they have the right to beat up women.' Other girls expressed the desire to seek legal justice from community structures, though when they attempted this avenue, they felt disregarded. As a 17-year-old girl from camp 2E commented: 'No one judges fairly if we complain. I complained to the head majhi. He only says that my husband will be good and drives us away. [I only complained] once. I understood that there will be no benefit.'

While unmarried Rohingya girls experience beatings by their parents if they fail to fulfil cultural expectations, our data suggest that this is less common-in the quantitative data, $14 \%$ of unmarried girls report that they have been pushed, slapped, hit, or beaten by a parent. A 16-year-old girl in camp 24 noted: '... whenever I go out, I am beaten up. Also I have to hide my Ludo board when father is here or he beats me. He tells me that that is bad. When my father is here, I cannot play.' Other reactions are more lenient, as an 18-year-old girl from camp 24 explained: 'If I make mistakes, no one at home beats me. They just scold me.' Most interviews found that parents resort to beatings if their daughters go out of the home, thus risking their honour of upholding purdah by community members who defame the girl's purity. This is particularly distressing for parents trying to organise suitable marriages for their daughters, who are meant to remain untainted by gossip. As a 42-year-old mother of an 18-year-old married girl explained, 'I don't have any desire to let my daughters go out, they will become bad. I am happy because my girls stay at home and no one can see them. [But] I am tense for other reasons like "Will I get a good proposal for my daughter?"'.

Overall, our qualitative data suggest that while unmarried girls may or may not face beatings, depending on the lenience of their parents, married girls typically do, as summed up during a focus group with adolescent girls in camp 24: 'I don't get beaten, as I don't have any husband.' 


\section{Psychosocial wellbeing}

Both married and unmarried Rohingya girls' realties are plagued with worries, particularly as they age through adolescence. Our qualitative data show that while major concerns and distress for married girls are centred on marital and household problems, common sources of worry for unmarried girls are centred on lack of finances, which hampers the chance of marriage, as well as limited educational opportunities and restricted mobility.

Our quantitative data find that $22 \%$ of girls exhibited signs of psychological distress, using the General Health Questionnaire (GHQ-12), an internationally validated measure of mental disorders and distress, and 23\% exhibit signs of being at least moderately depressed, using the Patient Health Questionnaire (PHQ-9), an internationally validated depression module. There is strong evidence suggesting worse mental health outcomes among married adolescents. Startlingly, while rates of psychological distress measured by the GHQ-12 are relatively similar (26\% among married girls and 20\% among unmarried girls, $p=0.119), 40.8 \%$ of married girls have PHQ-9 scores that classify them as exhibiting signs of being moderately to severely depressed, compared to only $14.9 \%$ of unmarried girls. ${ }^{6}$ The qualitative data also support greater sources of psychological distress for married girls, who are concerned about their husbands not paying attention to their or their children's needs, a lack of reliable household income, and social isolation. As an 18-year-old married girl in camp 2E explained, 'When my husband doesn't have work, I feel tensed. I also feel bad as I have not seen my friend since coming here. But we are married now. How will we meet?' Some married girls also displayed negative feelings about managing their household responsibilities since displacement and lamented more bountiful days in Myanmar. As an 18-year-old girl recalled, 'We had so many things in Burma. We used to grow vegetables there; we never had to buy any vegetables... We did not have so many problems with food there.' Married girls display worries about the future, particularly as they have neither money nor assets to pass on to their children. Although extremely low percentages for both cohorts, older unmarried girls appear more likely to report having money under their control than their married counterparts $(5.8 \%$ vs $0.1 \%)$.

Major concerns for unmarried girls relate to their household's financial situation and navigating cultural notions of appropriateness. Unmarried girls seem aware of changes in some community practices in the face of displacement-including opportunities for women to volunteer in camp structures and access skills-building classes-and are attempting to understand their place vis-à-vis these changes. A 17-year-old girl in camp 12 crystalised this sentiment, 'Here women can go out but in Burma you will be thrown out from society. Burma is the country of man but

\footnotetext{
${ }^{6}$ Moderate to severe depression is defined as having a PHQ-9 score of equal to or greater than 10 (Kroenke et al. 2001). Possible scores range from 0 to 27. These rates are in line with what has been found in other studies. For example, Patel et al. (2007), in synthesising prevalence of mental disorders from various studies of young people, find that" at least one out of every 4-5 young people in the population will suffer from at least one mental disorder in any given year," and prevalence is even higher among more vulnerable populations.
} 
Bangladesh is a country of women.' Moreover, unmarried girls are worried about securing a marriage proposal, and how their parents, lacking secure livelihoods, will afford a dowry - a concern exacerbated in female-headed households. Two 16-yearold unmarried girls from different camps expressed this tension:

People say, 'You are so old! Doesn't anyone propose to you for marriage?' Then I share it with my mother. My mother explains to them that we can't marry [me] off due to financial problems. (16-year-old girl, camp 24)

I don't think anything about the future. Marriage proposals come but they demand dowry. But we have no ability to give dowry. That's why I can't get married. They say, 'If you give this amount, I will marry you, otherwise I won't.' [They demand money] and utensils and the bride's family have to give dresses too for the groom. Dowry is a must during marriage however beautiful the girl is! (16-year-old girl, camp 2E)

Although all girls face restrictions on leisure time, particularly outdoors, many married girls have additional duties stemming from childcare, further binding them to their homes. In our sample of married girls in the quantitative data, 37\% reported having children. When asked about leisure time, a 17-year-old married girl in camp 24 replied, 'I say my prayer, read Qur'an, eat rice and serve food to others'. Although similarly confined to the home, some unmarried girls are allowed to meet in neighbours' houses to play indoor games and keep each other company. They also have more idle time to spend with friends inside their homes, and 'talk to each other and discuss dresses' (16-year-old girl, camp 2E). Unmarried girls are also able to have fun playing with younger brothers, nephews and neighbours' children without the responsibilities imposed by motherhood, as explained by a 16-year-old married girl in camp 2E speaking about her son, "My whole day is spent taking care of him."

In terms of support, married girls lament the loss of friendships due to their marital status. A 17-year-old married girl described, '[My friend and I] haven't met for so long. Now she has got married and I also have got married. Friendship has been over, that happens normally.' The loss of friendships affects all older adolescent girls, regardless of their marital status, due to age restrictions on mobility. In fact, both married and unmarried girls remembered friendships 'in my younger age' (17-year-old marred girl, camp 2E).

\section{Study limitations}

The empirical results reported here should be considered in the light of some limitations. Though our mixed-method research approach aims to produce more complete outcomes than using either method independently, our findings around IPV were more overtly pronounced in the qualitative data from the married sample as our survey module did not explicitly investigate IPV.

Second, specific nuances may have been lost in translation in both data collection and analysis. Though enumerators, interviewers, and the coding team were fluent in the Chittagonian dialect of Bangla, which is similar to the Rohingya language, some noteworthy discrepancies exist. We mitigated discrepancies by inserting specific 
Rohingya terminology into interview and survey guides once interviewers and enumerators had assimilated them, typically following the pilot phase. Learning specific Rohingya vocabulary can help us design tools for linguistic relevance in future rounds of data collection. Additionally, there are no words in Rohingya that capture specific psychological concepts-including anxiety, post-traumatic stress and depression (Tay et al. 2018).

\section{Discussion}

Our data present a complex picture of the vulnerabilities facing married Rohingya girls and the obstacles that prevent them gaining 'the kinds of assets that expand the capacity of individuals to achieve valued ways of "doing and being" (GAGE consortium 2019, p. 2). As soon as Rohingya girls enter adolescence, prevailing gender norms begin shaping their trajectories. Marriage becomes the predominant social role for girls who are married, and a dominant aspiration for unmarried girls and their families, reflecting Bourdieu's normalisation and reproduction of gender practices and norms (1977). All Rohingya adolescent girls living in Cox's Bazar face a myriad of vulnerabilities, yet to fully understand their lived realities it is important to disaggregate by marital status and to tailor policies and programming accordingly.

We find that certain forms of GBV, including IPV, go unreported due to cultural notions permitting a husband to behave violently towards his wife and notions that wives should not disclose intimate family matters. Married girls that reported domestic abuse received little support (whether mediation or legal counsel) from the majhi camp coordinators. As the discretionary powers of majhis grow, the system requires revisiting. Due to their integral role in camp life, we hope that majhis will be targeted and sensitised towards the bodily integrity risks faced by married girls and about the negative consequences of child marriage for adolescent girls' wellbeing and development trajectories. All community and religious leaders, including majhis should be prioritised as change agents for married adolescent girls experiencing GBV and be included as targeted beneficiaries of social norm interventions, including CIC messaging on the harmful effects and illegality of child marriage. Over time, majhis should lend their support to promote avenues for socialisation, including safe spaces for adolescent married girls who have lost their friendships and face social isolation due to the combined impacts of age, motherhood and the upholding of purdah.

Findings indicate that Rohingya displacement may, over time, lead to shifts in norms for married girls. More active participation of married girls in skills-building and income-generating activities could instigate these changes. The precarious status of the Rohingya in Cox's Bazar presents an opportunity to challenge prevailing gender norms and present alternative pathways that would otherwise be blindly replicated. Conflict and displacement are indeed known "trigger[s] for the bending of social norms, as women and girls often take on "male" economic roles... [and] the existence of economic opportunities available through migration has led to new social norms regarding female mobility, employment and education' (Marcus and Harper 2014, p. 18). 
Our findings illustrate twofold attitudes towards child marriage: on one hand, entrenched gender norms centred on seclusion and getting married have been reproduced within the 'doxa' (Bourdieu 1977) such that marriage continues to be the predominant concern for girls as they seek to maintain purdah and transition into adulthood. At the same time, our data match other reports (Wake et al. 2019; Goldsmith and Karim 2019) suggesting that female sewing and tailoring courses, at times home-based, are increasingly accepted and welcomed by the Rohingya community. We recommend leveraging this latter view by scaling-up programmes to provide outreach to married girls who have been largely excluded from participating, as well as extending participation to all adolescent girls. Adolescent training has in fact been highlighted as a key priority in the 2020 Joint Response Plan (ISCG et al. 2020), and this needs to include already married girls. To facilitate their access and retain their participation, we recommend that, initially, married girls report to female supervisors only that awareness-raising with family members is provided and that opportunities are either in close proximity to girls' homes with dedicated chaperones, or home-based (WRC 2019). To avoid backlash, it is critical that the empowerment of Rohingya married girls is coupled with a package of gender-transformative interventions around gender norms targeted to families and community leaders, also investigating the relationship between spouses regarding the appropriateness of female work.

Skills-building and income-generating initiatives may open a space for empowerment and socialisation for married adolescent girls who may also gain greater negotiation power in household decision-making when they earn some income. While the concept of empowerment requires an understanding of the multitude of confines, relations and internalised ideas of agency that girls must overcome and should not be boiled down to income generation, there is evidence that women's access to paid work can promote greater gender equality (Kabeer 2005). Additionally, exactly what empowerment means in the context of displacement and in the context of the very constrained options available to Rohingya girls, remains underexplored. While authors recognise the limitations of terminology, the material realities of girls' lives in this setting remain a very important concern and require attention.

\section{Conclusion}

Rohingya married girls are experiencing gender inequality in their daily lives leaving them at risk of multiple forms of GBV, including IPV, and social isolation. If Agenda 2030's central promise to leave no one behind is to be realised, it must not be viewed as a separate course of action, but intrinsic to fulfilling the Agenda as a whole. To meet SDG 5.3, more attention must be paid to and more data must be generated on already married girls, particularly in relation to evidence on components of successful interventions to respond to child marriage, in order to expose the context-specific drivers of child marriage and deepen our understanding of the vulnerabilities married girls face while also maintaining advocacy to prevent child marriage. Conflict and displacement can present an opportunity to tackle gender inequalities and progress transitions into adulthood for adolescent brides-an 
opportunity that must be grasped if we are to accelerate progress for married girls who are left behind.

Funding Funding was provided by Department for International Development, UK Government.

\section{Declarations}

Conflict of interest The authors of this paper report no known conflict of interest.

Open Access This article is licensed under a Creative Commons Attribution 4.0 International License, which permits use, sharing, adaptation, distribution and reproduction in any medium or format, as long as you give appropriate credit to the original author(s) and the source, provide a link to the Creative Commons licence, and indicate if changes were made. The images or other third party material in this article are included in the article's Creative Commons licence, unless indicated otherwise in a credit line to the material. If material is not included in the article's Creative Commons licence and your intended use is not permitted by statutory regulation or exceeds the permitted use, you will need to obtain permission directly from the copyright holder. To view a copy of this licence, visit http://creativecommons.org/licen ses/by/4.0\%.

\section{References}

ACAPS. 2019a. ACAPS thematic report: Rohingya Refugee Response, child-focused secondary data review. ACAPS.

ACAPS. 2019b. ACAPS thematic report: Vulnerabilities in the Rohingya Refugee Camps. ACAPS.

Ahmed, I. 2010. The plight of the stateless Rohingyas: Responses of the state, society \& the international community. Dhaka: The University Press Limited.

Ahsan, A.K.M., A.K.M. Ullah, and D. Chattoraj. 2018. Roots of discrimination against Rohingya minorities: Society ethnicity and international relations. Peace Review 26: 541-565.

Ainul, S., I. Ehsan, E.F. Haque, S. Amin, U. Rob, A. J. Melnikas, and J. Falcone. 2018. Marriage and sexual and reproductive health of Rohingya adolescents and youth in Bangladesh: A qualitative study. Dhaka, Bangladesh: Population Council.

Akhter, S., and K. Kusakabe. 2014. Gender-based violence among documented Rohingya refugees in Bangladesh. Indian Journal of Gender Studies 21 (2): 225-246. https://doi.org/10.1177/09715 21514525088.

Arab, R., and Mette Sagbakken. 2019. Child marriage of female Syrian refugees in Jordan and Lebanon: A literature review. Global Health Action. 12: 1585709. https://doi.org/10.1080/16549716.2019. 1585709 .

Baird, S., L. Camfield, A. A. Haque, A. Masri, K. Pincock, M. Puri, and N. Jones. 2020 Researching vulnerable adolescents in developing country contexts: a mixed methods approach. European Journal of Development Research (forthcoming).

Bourdieu, P. 1977. Outline of a theory of practice. Cambridge studies in social anthropology series. Cambridge: Cambridge University Press.

CARE International UK. 2015. To protect her honour: Child marriage in emergencies-The fatal confusion between protecting girls and sexual violence

Chakraborty, R. 2019. Child, not bride: Child marriage among Syrian refugees. Harvard International Review 40 (1): 20-21. https://doi.org/10.2307/26617388.

Cornwall, A. 2018. Beyond "Empowerment Lite": Women's empowerment, neoliberal development and global justice. Cadernos Pagu 58 (2018) https://doi.org/10.1590/18094449201800520002.

Cox's Bazar Panel Survey. 2019. Cox's Bazar Panel Survey Fact sheet. New Haven, United States: Innovations for poverty action and Yale MacMillan Center.

Desai, S., and G. Temsah. 2014. Muslim and Hindu women's public and private behaviors: Gender, family, and communalized politics in India. Demography 51 (6): 2307-2332. 
Freccero, J., and A. Whiting. 2018. Toward an end to child marriage: Lessons from research and practice in development and humanitarian sectors. Retrieved from https://www.law.berkeley.edu/wp-conte nt/uploads/2018/08/Toward-an-End-to-Child_Marriage_Report_FINAL.pdf

GAGE consortium. 2019. Gender and adolescence: Why understanding adolescent capabilities, change strategies and contexts matters. Second edition. London, UK: Gender and Adolescence: Global Evidence (GAGE)/Overseas Development Institute

Gender-based Violence (GBV) Area of Responsibility. 2017. Rohingya Crisis. GBV Policy and Advocacy Task Team, Inter-agency Briefing Paper. www.refugeesinternational.org/reports/2017/10/23/gbv.

Gender-based Violence Information Management System. 2019. Quarterly fact sheet: Refugee population data and nature of reported GBV cases. https://www.humanitarianresponse.info/en/operations/bangl adesh/gender-based-violence-gbv

Girls Not Brides and International Centre for Research on Women (ICRW). 2016. Taking action to address child marriage: The role of different sectors. London: Girls Not Brides.

Girls Not Brides. 2018. Child marriage in humanitarian settings. London: Girls Not Brides.

Goldsmith, B. and N. Karim. 2019. From sports to work, Rohingya women face new roles in world's largest refugee camp. Thompson Reuters Foundation, 6 February. http://news.trust.org/item/20190 206005130-d43p9/?fbclid=IwAR0tJKR2ZKI11ImSzjpQGZrkr4pIBkkGCdUJr0zKacxqxn9Ms20 svDvktec.

Guglielmi, S., J. Seager, K. Mitu, S. Baird, and N. Jones. 2020. Exploring the impacts of COVID-19 on Rohingya adolescents in Cox's Bazar: A mixed-methods study. Journal of Migration and Health 1 (2): 2020. https://doi.org/10.1016/j.jmh.2020.100031.

Holloway, K., and L. Fan. 2018. Dignity and the displaced Rohingya in Bangladesh. London: Overseas Development Institute.

Hossain, N. 2012. Women's empowerment revisited: From individual to collective power among the export sector workers of Bangladesh. IDS Working Paper No. 389. Brighton: IDS.

Hossain, M.K., and M. Kabir. 2001. Purdah, mobility and women's empowerment and reproductive behaviour in rural Bangladesh. Social Change 31 (3): 84-102. https://doi.org/10.1177/0049085701 03100307.

Hossain, M., A. Nabi, T. Ghafur, M.A. Haque, M.M. Islam, M. Khan, M.R. Haque, M. Islam, S. Roy, and M. Hasan. 2017. Context of child marriage and its implications in Bangladesh. Department of Population Sciences: University of Dhaka, Bangladesh.

Inter-Agency Standing Committee (IASC). 2015. Guidelines for integrating gender-based violence interventions in humanitarian action: reducing risk, promoting resilience and aiding recovery. https:// gbvguidelines.org/wp/wp-content/uploads/2015/09/2015-IASC-Gender-based-Violence-Guide lines_lo-res.pdf

Inter Sector Coordination Group (ISCG). 2017. Gender Profile No. 1 for Rohingya Refugee Response. Cox's Bazar, Bangladesh (as of December 2017).

Inter Sector Coordination Group (ISCG). 2019. Gender Profile No. 2 for Rohingya Refugee Response. Cox's Bazar, Bangladesh (as of March 2019). https://reliefweb.int/report/bangladesh/gender-profileno-2-rohingya-refugee-crisis-response-cox-s-bazar-bangladesh-march.

ISCG. 2018. Protection sector working group. Protection considerations on the 'Majhi System'. https:// reliefweb.int/report/bangladesh/protection-sector-working-group-cox-s-bazar-30-june-2018-prote ction-considerations

ISCG, IOM, UNHCR, and UN Resident Coordinator Bangladesh. 2019. 2019 joint response plan for Rohingya humanitarian crisis: January-December. www.humanitarianresponse.info/en/operations/ bangladesh/document/2019-joint-response-plan-rohingya-humanitarian-crisis-january

ISCG, IOM, UNHCR, and UN Resident Coordinator Bangladesh. 2020. Joint response plan: Rohingya humanitarian crisis: January-December 2020. www.humanitarianresponse.info/en/operations/ bangladesh/document/2020-joint-response-plan-rohingya-humanitarian-crisis-january

Johnsdotter, S., K. Moussa, A. Carlbom, R. Aregai, and B. Essén. 2009. "Never my daughters”. A qualitative study regarding attitude change towards female genital cutting among ethiopian and eritrean families in Sweden. Health Care for Women International 30 (1): 114-133.

Jones, N., S. Baird, J. Hicks, E. Presler-Marshall, T. Woldehanna, and W. Yadete. 2019b. Adolescent well-being in Ethiopia: exploring gendered capabilities, contexts and change strategies. A synthesis report on GAGE Ethiopia baseline ndings. London: Gender and Adolescence: Global Evidence

Jones, N., S. Baird, E. Presler-Marshall, A. Malachoswka, K. Kilburn, B.A. Hamad, A. Essaid, W. Amaireh, J. Sajdi, K. da Baniowe-, T. Alabbadi, S. Alheiwidi, Q. Ashareef, S. Altal, W. Kharabsheh, H.A. Taleb, M.A. Azzam, and B.A. Hammad. 2019a. Adolescent well-being in Jordan: 
Exploring gendered capabilities, contexts and change strategies. A synthesis report on GAGE Jordan baseline ndings. London: Gender and Adolescence: Global Evidence.

Kabeer, N. 2005. Gender equality and women's empowerment: A critical analysis of the third millennium development goal 1. Gender \& Development 13 (1): 13-24. https://doi.org/10.1080/1355207051 2331332273.

Kabeer, N., A. Khan, and N. Adlparvar. 2011. Afghan values or women's rights? Gendered narratives about continuity and change in Urban Afghanistan. Working Paper 387. Brighton: IDS.

Keleher, H., and L. Franklin. 2008. Changing gendered norms about women and girls at the level of household and community: A review of the evidence. Global Public Health: An International Journal for Research, Policy and Practice 3 (S1): 42-57.

Khosla, N. 2009. The ready made garments industry in Bangladesh: A means to reducing gender based social exclusion of women. Journal of International Women's Studies 11.

Kroenke, K., R.L. Spitzer, and J.B. Williams. 2001. The PHQ-9: Validity of a brief depression severity measure. Journal of General Internal Medicine. 16 (9): 606-613. https://doi.org/10.1046/j.15251497.2001.016009606.x.PMID:11556941;PMCID:PMC1495268.

Kingston, Lindsey. 2015. Protecting the world's most persecuted: The responsibility to protect and Burma's Rohingya minority. The International Journal of Human Rights. 19: 1-13. https://doi.org/10. 1080/13642987.2015.1082831.

Leigh, J., et al. 2020. Child marriage in humanitarian settings in South Asia: Study results from Bangladesh and Nepal. UNFPA APRO and UNICEF ROSA.

Lewa, C. 2008. Asia's new boat people. Forced Migration Review (30): 40-42

Marcus, R., and C. Harper. 2014. Gender justice and social norms-Processes of change for adolescent girls: Towards a Conceptual Framework 2. London: Overseas Development Institute.

Mazurana, D., and A. Marshak. 2019. Addressing data gaps on child, early and forced marriage in humanitarian settings. Save the Children, White Paper and Discussion Draft December 2019.

Melnikas, A.J., S. Ainul, I. Ehsan, E. Haque, and S. Amin. 2020. Child marriage practices among the Rohingya in Bangladesh. Confl Health 14: 28.

Milton, A.H., M. Rahman, S. Hussain, C. Jindal, S. Choudhury, S. Akter, S. Ferdousi, T.A. Mouly, J. Hall, and J.T. Efird. 2017. Trapped in statelessness: Rohingya refugees in Bangladesh. International Journal of Environmental Research and Public Health 14 (8): E942.

Mourtada, R., J. Schlecht, and J. DeJong. 2017. A qualitative study exploring child marriage practices among Syrian conflict-affected populations in Lebanon. Conflict and Health 11 (S1): 27.

Munoz Boudet, A. M., P. Petesch, and C. Turk, A. Thumala. 2012. On norms and agency. Conversations about gender equality with women and men in 20 countries. Washington, DC: World Bank.

Murphy, M. 2013. The girl: Mergers of feminism and finance in neoliberal times. The Scholar and Feminist Online 11.2. http://sfonline.barnard.edu/gender-justice-and-neoliberal-transformations/the-girlmergers-of-feminism-and-finance-in-neoliberal-times/

Murphy, M., D. Arango, A. Hill, M. Conteras, M. MacRae, and M. Ellsberg. 2016. What works to prevent and respond to violence against women and girls in conflict and humanitarian settings? https:// reliefweb.int/report/world/what-works-prevent-respond-violence-against-women-and-girls-conflictand-humanitarian

OHCHR. 2017. Resolution adopted by the Human Rights Council on 22 June 2017 on Child, Early and Forced Marriage in Humanitarian Settings: A/HRC/RES/35/16. Office of the High Commissioner for Human Rights. https://ap.ohchr.org/documents/dpage_e.aspx?si=A/HRC/RES/35/16.

Patel, V., A.J. Flisher, S. Hetrick, and P. McGorry. 2007. Mental health of young people: A global publichealth challenge. The Lancet 369 (9569): 1302-1313.

Pincock, K. 2018. School, sexuality and problematic girlhoods: Reframing 'empowerment' discourse. Third World Quarterly 39 (5): 906-919. https://doi.org/10.1080/01436597.2017.1415141.

PLAN International and GPS. 2018. Adolescent girls in crisis: Voices of the Rohingya. Woking, UK: Plan International.

Presler-Marshall, E., N. Jones, S. Alheiwidi, S. Youssef, Hamad, B.A., K. Bani Odeh, S. Baird, E. Oakley, S. Guglielmi and A. Małachowska. 2020. Through their eyes: exploring the colmplex drivers of child marriage in humanitarian contexts. Report. London: Gender and Adolescence: Global Evidence.

Rahman, M. M., and H. Mohajan. 2019. Rohingya-The stateless community becoming the lost generation. Journal of Economic Development, Environment and People 8(2): 24-36. https://doi.org/10. 26458/jedep.v8i2.621 
Rao, N. 2012. Breadwinners and homemakers: Migration and changing conjugal expectations in rural Bangladesh. Journal of Development Studies 48 (1): 26-40.

Ripoll, S. 2017. Social and cultural factors shaping health and nutrition, wellbeing and protection of the rohingya within a humanitarian context. Social Science in Humanitarian Action, a Partnership between UNICEF, the Institute of Development Studies (IDS) and Anthrologica.

Save the Children. 2019. Ending child marriage in humanitarian settings: Ensuring accountability to girls though improved data collection, analysis and use. https://resourcecentre.savethechildren.net/ node/15239/pdf/wd_cefm_in_humanitarian_settings_database_2pger.final.pdf

Sen, G., P. Ostlin, and A. George. 2007 Unequal, unfair, ineffective and inefficient gender inequity in health: why it exists and how we can change it. Final report to the WHO Commission on Social Determinants of Health.

Siddiqi, M., and M. Greene. 2019. Mapping the eld: A system- atic scoping study of child marriage research, 2013-2019. Washington, DC: GreeneWorks.

Sullivan, D. 2020. A voice in their future: The need to empower Rohingya refugees in Bangladesh. Washington, DC: Refugees International.

Tay, A.K., R. Islam, A. Riley, C. Welton-Mitchell, B. Duchesne, V. Waters, A. Varner, D. Silove, and P. Ventevogel. 2018. Culture, context and mental health of Rohingya Refugees: A review for staff in mental health and psychosocial support programmes for Rohingya Refugees. Geneva: United Nations High Commissioner for Refugees (UNHCR).

Toma, I., M. Chowdhury, M. Laiju, N. Gora, and N. Padamada. 2018. Rohingya refugee response gender analysis: Recognizing and responding to gender inequalities. Action Contre La Faim, Save the Children, and Oxfam. https://policy-practice.oxfam.org.uk/publications/rohingya-refugee-responsegender-analysis-recognizing-and-responding-to-gender-620528.

UNFPA. 2017. New study finds child marriage rising among most vulnerable Syrian refugees. United Nations Population Fund, 31 January.

UNHCR. 2017. Mixed-movements in South East Asia, 2016. https://www.refworld.org/docid/590b1 8a14.html. As cited in GBV Policy and Advocacy Task Team Inter-agency Briefing Paper (October 2017), GBV Sub Sector, ISCG, Cox's Bazar, Bangladesh

UNHCR. 2019a. Rohingya Emergency. https://www.unhcr.org/rohingya-emergency.html

UNHCR. 2019b. Rohingya refugee crisis: Registration of the marriages and divorces of refugees. https:// reliefweb.int/report/bangladesh/rohingya-refugee-crisis-registration-marriages-and-divorces-refug ees

UNHCR. 2020. Global Trends: Forced Displacement in 2019. Geneva: UNHCR. https://www.unhcr.org/ 5ee200e37/

UNHCR, UNICEF, WFP. 2018. VASyR 2018: Vulnerability assessment of Syrian Refugees in Lebanon. https://www.unhcr.org/lb/wp-content/uploads/sites/16/2018/12/VASyR-2018.pdf

Wake, C., V. Barbelet, and M. Skinner. 2019. Rohingya Refugees' perspectives on their displacement in Bangladesh: Uncertain futures. HPG Working Paper. London: Overseas Development Institute.

Watson, C. 2012. Gendered Social Institutions, Young Women and Girls: Overview of Key Analytical Perspectives and Policy Thrusts for Further Reflection. Critical Assessment Paper produced by the Overseas Development Institute for DFID-Supported Flagship Programme 4: Transforming the Lives of Girls and Young Women. London: Overseas Development Institute.

Women's Refugee Commission (WRC). 2016. A girl no more: The changing norms of child marriage in conflict. Washington, DC: Women's Refugee Commission.

Women's Refugee Commission (WRC). 2019. 'We need to write our own names': Gender equality and women's empower- ment in the Rohingya humanitarian response in Cox's Bazar. Gender Operational Review Report. New York: WRC

Publisher's Note Springer Nature remains neutral with regard to jurisdictional claims in published maps and institutional affiliations. 